\title{
Allocation of DG Units for Loss Minimization in Distribution Network
}

\author{
Komal Sharma, Sarfaraz Nawaz \\ Department of Electrical Engineering, Swami Keshvanand Institute of Technology, Management \& Gramothan, Jaipur- \\ 302017 (INDIA) \\ Email: kmlsharma2010@gmail.com, sarfaraz@skit.ac.in \\ Received 17.03.2021, received in revised form 11.10.2021, accepted 11.10.2021 \\ doi: 10.47904/IJSKIT.11.2.2021.50-54
}

\begin{abstract}
In terms of technological advancement, DGs take part in minimizing power losses in the distribution system so as to achieve load requirements. An increase in power production has been capable of meeting growing demands at loading stations for the distribution system. One way to meet the essential load demand is to decrease the overall losses in distribution system. By lowering the reactive power losses of the system, actual power can be increased over the network. Therefore, in the distribution system by optimally allocating the DGs in distribution system we can decrease the power losses. The aim of the paper is to decide the best possible site and size of DG units to curtail the total reactive power losses \& thereby reducing real power losses while keeping better voltages in distribution network. This paper work suggested an analytical method and also a new constant that identify the best optimally rating \& site of DG. An objective function is presented to find the reactive power loss when fortified with DGs. The technique is experienced on standard IEEE 33 bus systems. The obtained results demonstrate that RPL reduction in RDS is feasible as compared to others.
\end{abstract}

Keywords- Distributed Generation (DG), Distribution Network (DN), Radial Distribution System (RDS), Power voltage Sensitivity Factor (PVSF), Reactive Power Loss (RPL) Minimization, Single line diagram (SLD).

\section{INTRODUCTION}

In India the power distribution system has faced many challenges and needs to follow new benchmarks on a daily basis. In India one of the biggest challenges for electrical utilities is the reduction in revenue losses. The distribution of power in the electrical system is the final and most important link. The direct effect on the discomfort of commercial viability and also on stakeholders who pay for electricity in the form of a tariff is due to a high overall technological and commercial loss. The pressure to increase the overall power delivery competence has forced the power utilities, particularly at the level of distribution, to reduce the losses. The key motive of the paper is to determine the best location of DG units, in order to enhance distribution system performance in terms of total RPL reduction. Distributed generators (DGs), which are placed near to the consumer, can improve performance, reduce losses, reduce price, improve bus voltages, and improve the reliability of network [1]. N. Khalesi [2] presented a dynamic programming which is effective to find the best possible sitting of DGs in distribution system. This programming helps in minimizing the power loss, enhance the system reliability and bus voltages. Sayyid Mohssen Sajjadi [3] considered the simultaneous positioning of DG at different load levels in the distribution network. In it Memetic Algorithim is employed to solve the problems of loss minimization, enhancement of bus voltages. Duong Quoc Hung [4] examined the problem of multiple distributed generators (DG units) installation in large-scale primary distribution networks in order to obtain a high loss of decrement. IA approach was presented in this review.

In order to reduce power losses, Peyman Karimyan [5] suggested a novel long-lasting planning for best possible size and positioning of various kinds of DGs in the DN. A latest approach evolved from PSO and also an analytical approach has been introduced in this context. The authors T. Yuvaraj and K.R. Devabalaji [6] aimed to address best position \& size of DGs in DN with the help of Bat Algorithm which is inspired by nature (BA). Kumar Mahesh [7] implemented a latest approach APSO to lessen overall device loss of power. Pankita Mehta [8] implied a technique Comprehensive Continuous Power Flow Analysis (CPF) for finding the best possible position \& kind of DGs among various kinds that be able to improve voltage stability. Mohammadreza Vatani [9] established an integration of GA with analytical methods used to optimize the position of no of DGs in the DN to lessen the losses in the system. U. Sultana [10] presented the recent trend of optimally placing DGs with several feature objectives, comprising improvement of voltage stability, improvement of bus voltages \& reduction in energy loss. Fahad S. Abu-Mouti [11] introduced $\mathrm{ABC}$ algorithm to decide the most favorable rating, P.F and position of the DG-unit for the sake of decreasing the overall system's actual power loss. S.A. Chithra Devi [12] proposed the Stud Krill herd Algorithm (SKHA) to discover the most advantageous position and rating of DG in a radial DN. Nand K. Meena [13] suggested the utilization of optimization technique of Taguchi for the optimally positioning of DGs in DN to mitigate loss of power though preserving the allowable DG integration limit $\&$ different device boundaries. S. Nawaz et al. [14] introduced a mathematical expression to resolve the issue of placement and rating of DG to decrease 
overall losses in primary distribution system. J. Shanmugapriyan [15] proposed an efficient approach for determining the optimum role in the distribution system of multi-type DG. Using the distributed generation suitability index (DGSI), PSO algorithm and DE are applied to define the correct position and size of DG. Sirine Essallah [16] suggested a new approach to distributed generation (DG) positioning and sizing, maintaining voltage stability and decreasing overall losses of power in electricity grid. The authors K. Sharma and S. Nawaz [17] aimed to address the most favorable position and size of DGs in DN to lessen reactive power loss by using analytical method.

This paper work describes a convenient and straightforward approach for reducing RPL in the RDS using DG. The PVSF is used to discover the rating \& site of the DGs. The proposed approach is executed in MATLAB and examined on a standard 33-bus RDS. The effectiveness of the suggested method has been validated using the latest method found in literature.

\section{PROBLEM FORMULATION}

The primary objective of the paper is to decrease the RPL in the radial distribution system by optimally placing and sizing the DG units. A nonlinear objective function is given in (1).

The overall RPL minimization is taken account as objective function [17]:

$$
\text { Minimize } f=\min \left(Q_{O R P L}\right)
$$

Where $Q_{\text {ORPL }}=$ Overall RPL

Two buses $\mathrm{z}$ and $\mathrm{z}+1$ are shown in fig. 1. The reactive power $Q_{k, k+1}$ moving into the buses $\mathrm{z}$ and $\mathrm{z}+1$ are shown in fig.1. The RPL in (2) into the buses $z$ and $z$ +1 in the line segment are calculated as:

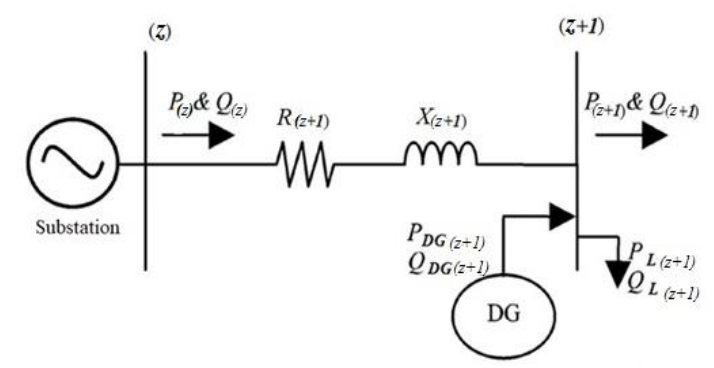

Fig.1 SLD of Radial DN with DG Connection

The RPL in (2) into the buses $\mathrm{z}$ and $\mathrm{z}+1$ in the line segment are calculated here:

$$
\begin{aligned}
& Q_{\text {loss }(z, z+1)}=\left(\frac{P_{z, z+1}^{2}+Q_{z, z+1}^{2}}{\left|V_{z+1}\right|^{2}}\right) \times X_{z} \\
& Q_{O R P L}=\sum_{z=1}^{b} Q_{\text {loss }(z, z+1)}
\end{aligned}
$$

Where

$\mathrm{b}=$ overall no. of branches

The above-mentioned objective function depends on limits as:
i. Equality Constraints
ii. Active power compensation
iii. Thermal limit

\section{PROPOSED METHODOLOGY}

This part explains the proposed analytical approach. This approach depends on the PVSF. This method determines the best value of DGs and location with managing the limitations and minimizing reactive power loss. Actual power is used to do productive work, and reactive power is used to maintain the voltage, which must be regulated for device efficiency. Since voltages in the system are influenced by reactive power, it has a major impact on power security issues. Actual power and reactive power of various loads differ depending on voltage magnitude. Variation in voltage occurs due to variation in reactive power flow. If reactive power produced is more than the power consumed, the levels of voltage are going up and vice versa. And the reactive power tends to varying due to different types of loads. Thus, by controlling reactive power flow and reducing RPLs the average power flow in a system can be maximized. And a flat bus voltage at all levels of the system can be maintained. In the paper the algorithm for calculating DG size and site is taken from [17].

\subsection{DG penetration factor (DGPF)}

Researchers don't typically calculate the DG penetration factor. In certain instances, the value of a DG unit is not feasible due to financial constraints. Although we all know that larger values of DG lessens the losses significantly but at a heavy price. As a result, the size of the DG is reduced significantly, as this would otherwise result in a higher system price. DGPF calculates the percentage power loss reduction for the DG's unit size. Its optimum value represents the smallest DG with the least amount of losses.

$$
D G P F=\frac{\text { Loss reduction in percentage }}{\text { Overall size of } D G}
$$

For optimally allocating the DGs in RDS the value of DGPF must be highest. 


\section{RESULTS}

The proposed technique is implemented on IEEE 33bus system. To illustrate the results, three distinct loading scenarios are defined in this paper work as: fifty percentage load, hundred percentage load, and one hundred sixty percentage load. The outcomes of the proposed analytical technique without and with the DG placement are tabulated and also the comparative analysis of the test system is provided in this section.

\subsection{Test System}

The overall load of 33 bus system is $3.715 \mathrm{MW}$ and 2.30 MVAr. Base quantities are $12.66 \mathrm{kV}$ and 100 MVA.

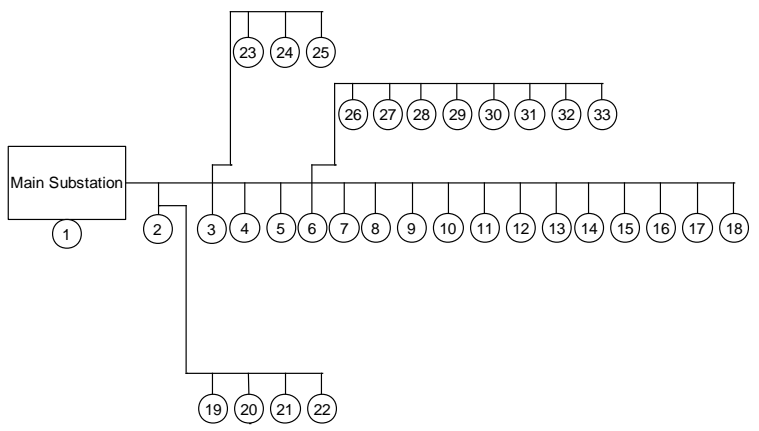

Fig. 2. IEEE 33 bus test System of RDS

Table I shows the outcomes of three separate loading scenarios as fifty percentage load, hundred percentage load and one hundred sixty percentage load. The reactive power losses before placing the DG units are $31.35 \mathrm{kVAr}$ for fifty percentage load, $135.14 \mathrm{kVAr}$ for hundred percentage load and 384.26 $\mathrm{kVAr}$ for one hundred sixty percentage load. And the Vmin before placing the DG units for different loading conditions as fifty percentage, hundred percentage and one hundred sixty percentage load patterns are as 0.9583 per unit, 0.9131 per unit and 0.8528 per unit respectively. By using PVSF, size and location of DG are computed. As can be seen in Table I, the best bus positions are bus numbers 14, 27, and 31 , which are evenly suitable for every load patterns and given in it.

After placing the DG(s) at most advantageous bus positions RPLs are decreased to $13.95 \mathrm{kVAr}, 57.64$ $\mathrm{kVAr}, 160.69 \mathrm{kVAr}$ with enhanced voltage profile of 0.9806 per unit, 0.9605 per unit and 0.9290 per unit on fifty percentage load, hundred percentage load and one hundred sixty percentage load respectively. In this context, it is clear that RPL is decreased \& bus voltages enhanced by this analytical technique. As well as here in table I we can see that real power losses also minimized with reactive power loss reduction which is greatest reward for the radial distribution system.
Table 1: Test Results

\begin{tabular}{|c|c|c|c|c|}
\hline \multirow{4}{*}{$\begin{array}{l}\text { Befor } \\
\text { e } \\
\text { Placin } \\
\text { g DG }\end{array}$} & \multirow[t]{2}{*}{ Indices } & \multicolumn{3}{|c|}{ Load Level } \\
\hline & & $\begin{array}{l}50 \\
\text { percenta } \\
\text { ge }\end{array}$ & $\begin{array}{l}100 \\
\text { percenta } \\
\text { ge }\end{array}$ & $\begin{array}{l}160 \\
\text { percenta } \\
\text { ge }\end{array}$ \\
\hline & $\begin{array}{l}\text { Reactive } \\
\text { Power Loss } \\
\text { in kVAr }\end{array}$ & 31.35 & 135.14 & 384.26 \\
\hline & $\begin{array}{l}\text { Real Power } \\
\text { Loss in kW }\end{array}$ & 47 & 202.7 & 575.36 \\
\hline & $\mathrm{V}_{\min }$ in $\mathrm{pu}$ & 0.96 & 0.91 & 0.86 \\
\hline $\begin{array}{l}\text { After } \\
\text { Placin } \\
\text { g DG }\end{array}$ & $\begin{array}{l}\text { size of DG } \\
\text { in }(\mathrm{kW}) \\
\text { [Location] }\end{array}$ & $\begin{array}{l}297[14] \\
240[27] \\
316[31]\end{array}$ & $\begin{array}{l}595[14] \\
500[27] \\
630[31]\end{array}$ & $\begin{array}{l}830[14] \\
720[27] \\
1010[31]\end{array}$ \\
\hline & $\begin{array}{l}\text { Overall } \\
\text { size of DG } \\
\text { in } \mathrm{kW}\end{array}$ & 853 & 1725 & 2560 \\
\hline & $\begin{array}{l}\text { Reactive } \\
\text { Power } \\
\text { Losses in } \\
\text { kVAr }\end{array}$ & 13.95 & 57.64 & 160.69 \\
\hline & $\begin{array}{l}\text { Real } \\
\text { Power } \\
\text { Losses in } \\
\mathrm{kW}\end{array}$ & 20.73 & 85.66 & 239.33 \\
\hline & $\mathrm{V}_{\min }$ in $\mathrm{pu}$ & 0.9806 & 0.9605 & 0.9290 \\
\hline & $\begin{array}{l}\text { percentage } \\
\text { Loss } \\
\text { minimizati } \\
\text { on in } \\
\text { reactive } \\
\text { power }\end{array}$ & 55.50 & $\mathbf{5 7 . 3 4}$ & 58.18 \\
\hline & $\begin{array}{l}\text { percentage } \\
\text { Loss } \\
\text { minimizati } \\
\text { on in real } \\
\text { power }\end{array}$ & 55.89 & 57.74 & 58.40 \\
\hline
\end{tabular}

The attained results of 33 bus system at hundred percentage load condition are compared with metaheuristic techniques identified in literature as hybridization of analytical method and heuristic search method [18], BAT algorithm [19], BFOA [20], HTLBO [21]. Table II presents comparison of outcomes which reveals decrement in RPL together with actual power loss in terms of DGPF. The Maximum value of DGPF shows the minimum size of DG with higher value of percentage loss reduction. Table II indicates that the size of DGs in such methods is very large, while the size of DGs in the proposed analytical method is much smaller. And in the proposed analytical method the DGPF value is highest which is prominent in terms of percentage power loss reduction.

Table II also manifest that after a particular level of DG penetration the percentage power loss reduction decreases. It is shown in HTLBO method where the percentage loss reduction drops due to higher level of DG penetration as compared to given methods. So the level of DG penetration should be maintained appropriately which is provided in proposed 
analytical method. In above mentioned method value of DGPF is 0.034 (at hundred percentage load) and its value is highest.

Table 2: Comparative Analysis

\begin{tabular}{|c|c|c|c|l|}
\hline Methods & $\begin{array}{c}\text { Overall } \\
\text { size } \\
\text { of DG } \\
\text { (kW) }\end{array}$ & $\begin{array}{c}\text { Percentage } \\
\text { Loss } \\
\text { Minimizatio } \\
\text { n in Reactive } \\
\text { Power }\end{array}$ & $\begin{array}{c}\text { Percentage } \\
\text { Loss } \\
\text { Minimizatio } \\
\text { n in Active } \\
\text { Power }\end{array}$ & DGPF \\
\hline $\begin{array}{c}\text { Hybridization } \\
\text { of analytical } \\
\text { method and } \\
\text { heuristic } \\
\text { search (2016) } \\
{[18]}\end{array}$ & 2870 & 63.45 & 65.45 & 0.022 \\
\hline $\begin{array}{c}\text { BAT (2016) } \\
{[19]}\end{array}$ & 2721 & 62.27 & 64.42 & 0.023 \\
\hline $\begin{array}{c}\text { BFOA (2016) } \\
{[20]}\end{array}$ & 2742 & 63.16 & 65.14 & 0.023 \\
\hline $\begin{array}{c}\text { HTLBO (2019) } \\
{[21]}\end{array}$ & 3709.6 & 50.58 & 52.78 & 0.014 \\
\hline $\begin{array}{c}\text { Proposed } \\
\text { Method }\end{array}$ & $\mathbf{1 7 2 5}$ & $\mathbf{5 7 . 3 4}$ & $\mathbf{5 7 . 7 4}$ & $\mathbf{0 . 0 3 4}$ \\
\hline
\end{tabular}

Fig. 3 exhibits bus voltages by putting the DG and not putting the DG at fifty percentage load in the system. In the proposed approach, the voltage profiles are boosted.

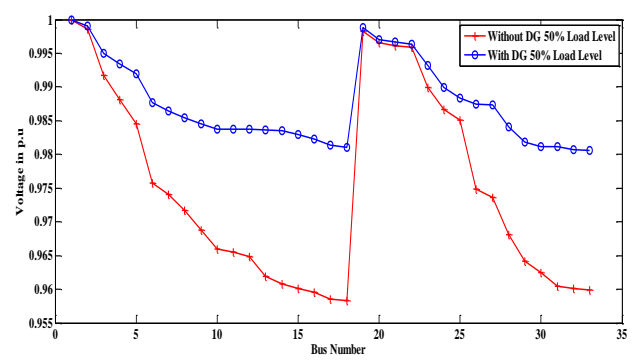

Fig. 3. Bus Voltages at fifty percentage load level

Fig. 4 exhibits bus voltages by putting the DG and not putting the DG at hundred percentage load in the system. In the proposed approach, the voltage profiles are boosted.

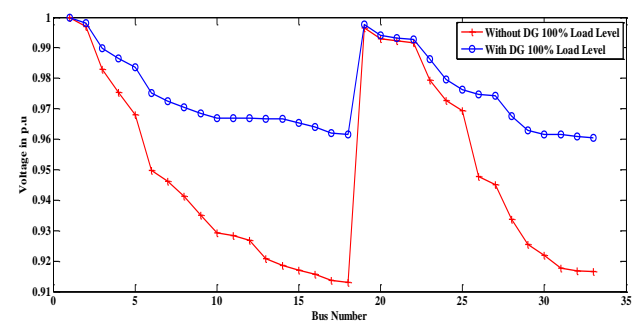

Fig. 4. BusVoltages at hundred percentage load level

Figure 5 exhibits bus voltages by putting the DG and not putting the DG at one hundred sixty percentage load in the system. In the proposed approach, the voltage profiles are boosted.

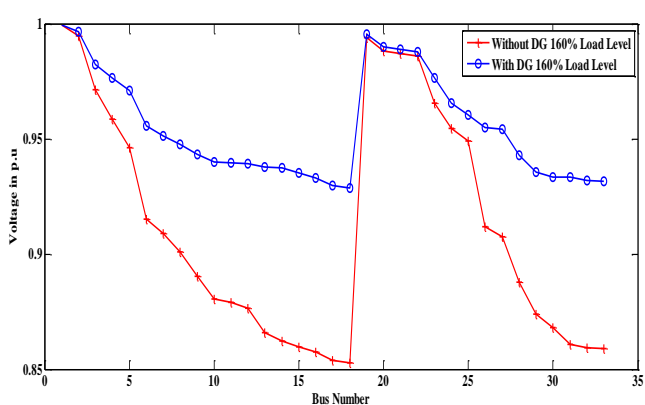

Fig. 5. Bus Voltages at one hundred sixty percentage load level

\section{CONCLUSION}

In conclusion, this paper work manifests the development and implementation of a new analytical approach to help minimize system reactive power losses as well as actual power loss by optimizing the position and size of the DG(s). The PVSF was formulated in it to obtain the value of DGs \& location of DG units in the distribution network. Also taken into account is the DGPF component, which shows the minimization in percentage power loss per unit size of DG. While actual power loss mitigation has been addressed in previous research papers, but here the effect of RPL on actual power requirement is investigated here. Here the work done by this method demonstrates a raise in percentage loss minimization of reactive power as well as actual power and improved bus voltages. For three different loading conditions, this analytical method was applied on the 33 bus RDS. Finally, previous approaches are compared in the paper, it can be said that the work described in this study provides the most satisfactory and reasonable results.

\section{REFERENCES}

[1] Partha P Biswas, Rammohan Mallipeddi, Ponnuthurai N Suganthan, and Gehan AJ Amaratunga. A multiobjective approach for optimal placementand sizing of distributed generators and capacitors in distribution network. Applied Soft Computing, 60:268-280, 2017.

[2] N Khalesi, Nariman Rezaei, and M-R Haghifam. Dg allocation with applica-tion of dynamic programming for loss reduction and reliability improvement.International Journal of Electrical Power \& Energy Systems, 33(2):288295, 2011.

[3] Sayyid Mohssen Sajjadi, Mahmoud-Reza Haghifam, and Javad Salehi. Simultaneous placement of distributed generation and capacitors in distribution networks considering voltage stability index. International Journal of Electrical Power \& Energy Systems, 46:366-375, 2013.

[4] D. Q. Hung and N. Mithulananthan. Multiple distributed generator place-ment in primary distribution networks for loss reduction. IEEE Transactionson Industrial Electronics, 60(4):1700-1708, 2013.

[5] Peyman Karimyan, Gevork B Gharehpetian, M Abedi, and Adnan Gavili.Long term scheduling for optimal allocation and sizing of $\mathrm{dg}$ unit consideringload variations and $\mathrm{dg}$ type.International Journal of Electrical Power \&Energy Systems, 54:277-287, 2014.

[6] T Yuvaraj, KR Devabalaji, and K Ravi. Optimal allocation of $\mathrm{dg}$ in theradial distribution network using bat optimization 
algorithm. InAdvancesin power systems and energy management, pages 563-569. Springer, 2018.

[7] Kumar Mahesh, Perumal AL Nallagownden, and Irraivan AL Elamvazuthi. Optimal placement and sizing of $\mathrm{dg}$ in distribution system using accelerated pso for power loss minimization. In2015 IEEE Conference on Energy Conversion (CENCON), pages 193-198. IEEE, 2015.

[8] Pankita Mehta, Praghnesh Bhatt, and Vivek Pandya. Optimal selection of distributed generating units and its placement for voltage stability enhancement and energy loss minimization. 2015.

[9] Mohammadreza Vatani, Davood Solati Alkaran, Mohammad Javad Sanjari,and Gevork B Gharehpetian. Multiple distributed generation units alloca-tion in distribution network for loss reduction based on a combination ofanalytical and genetic algorithm methods.IET Generation, Transmission\& Distribution, 10(1):66-72, 2016.

[10] U Sultana, Azhar B Khairuddin, MM Aman, AS Mokhtar, and $\mathrm{N}$ Zareen. A review of optimum dg placement based on minimization of power losses and voltage stability enhancement of distribution system. Renewable and Sustainable Energy Reviews, 63:363-378, 2016.

[11] Fahad S Abu-Mouti and ME El-Hawary. Optimal distributed generation al-location and sizing in distribution systems via artificial bee colony algorithm. IEEE transactions on power delivery, 26(4):2090-2101, 2011.

[12] SA ChithraDevi, L Lakshminarasimman, and $\mathrm{R}$ Balamurugan. Stud krill herd algorithm for multiple $\mathrm{dg}$ placement and sizing in a radial distribution system. Engineering Science and Technology, an International Journal, 20(2):748-759, 2017.

[13] Nand K Meena, Anil Swarnkar, Nikhil Gupta, and KR Niazi. A taguchi-based approach for optimal placement of distributed generations for power loss minimization in distribution system. In 2015 IEEE Power \& Energy Society General Meeting, pages 1-5. IEEE, 2015.
[14] Sarfaraz Nawaz, Md Imran, and Sonali Singh. A novel approach for multiple dg allocation in distribution system of jaipur city. In 2017 International Conference on Information, Communication, Instrumentation and Control (ICICIC), pages 1-6. IEEE, 2017.

[15] Shanmugapriyan, N Karuppiah, S Muthubalaji, and S Tamilselvi. Optimum placement of multi type dg units for loss reduction in a radial distribution system considering the distributed generation. Bulletin of the Polish Academy of Sciences. Technical Sciences, 66(3), 2018.

[16] Sirine Essallah, Adel Khedher, and Adel Bouallegue. Integration of distributed generation in electrical grid: Optimal placement and sizing under different load conditions. Computers \& Electrical Engineering, 79:106461,2019.

[17] Komal Sharma and Sarfaraz Nawaz. Allocation of dg units in distributionsystem to minimize reactive power loss. In2020 5th IEEE InternationalConference on Recent Advances and Innovations in Engineering (ICRAIE),pages 1-5. IEEE, 2020.

[18] Satish Kansal, Vishal Kumar, and Barjeev Tyagi. Hybrid approach foroptimal placement of multiple dgs of multiple types in distribution networks.International Journal of Electrical Power \& Energy Systems, 75:226-235,2016.

[19] Suresh Kumar Sudabattula and M Kowsalya. Optimal allocation of solar based distributed generators in distribution system using bat algorithm. Perspectives in Science, 8:270 272, 2016.

[20] KR Devabalaji and K Ravi. Optimal size and siting of multiple $\mathrm{dg}$ anddstatcom in radial distribution system using bacterial foraging optimizationalgorithm.Ain Shams Engineering Journal, 7(3):959-971, 2016

[21] Imran Ahmad Quadri, Suman Bhowmick, and Dheeraj Joshi. A hybrid teaching learning-based optimization technique for optimal dg sizing and placement in radial distribution systems. Soft Computing, 23(20):9899-9917, 2019. 